\title{
COVID-19 and Online Learning: A SWOT Analysis of Users' Perspectives on Learning Management System of University of Education, Winneba, Ghana
}

\author{
Dandy George Dampson, Richardson Addai-Mununkum, \\ Stephen Kwakye Apau and Joseph Bentil \\ University of Education, Winneba, Ghana \\ https://orcid.org/0000-0002-7185-7189 \\ https://orcid.org/0000-0003-3144-5005 \\ https://orcid.org/0000-0001-9010-8514 \\ https://orcid.org/0000-0002-2755-0171
}

\begin{abstract}
This study investigated users' perceptions of the University of Education, Winneba (UEW) Learning Management Systems (LMS) based on SWOT. The study adopted the explanatory sequential mixed methods which sampled 3272 students and 20 lecturers by using the stratified and purposive sampling techniques, respectively. The study used questionnaires and semi-structured interview guides to collect quantitative and qualitative data. Quantitative data were analyzed using Means and Standard Deviations, Independent Samples t-test, and ANOVA. The qualitative data was analyzed thematically. The study found that UEW LMS is perceived to have elements of weaknesses and threats as well as strengths and opportunities. The study further found that the users of LMS differ in their perceptions in terms of SWOT based on students' age. The students, however, did not differ significantly in their perceptions of SWOT based on gender. The study recommended that the management of UEW LMS need to educate both lecturers and students about the benefits that LMS offers to its users. Management of the UEW should make the usage of the LMS compulsory for teaching and learning while taking into consideration the age of the students in the designing and implementation of subsequent online platforms for students and lecturers.
\end{abstract}

Keywords: COVID-19; education; gender; pandemic; pedagogy

\section{Introduction}

Following the outbreak of Corona virus disease (COVID-19) and the subsequent closure of all universities in Ghana, the Government through the Ministry of Education as well as the National Council for Tertiary Education instructed all 
Vice-Chancellors in Ghana to ensure that there was no disruption in the academic calendar. It is in line with this directive that the University of Education, Winneba (UEW) fully deployed its Learning Management System (LMS) for use to its over 85,000 student population. Consequently, UEW has migrated over 2,104 courses and over 54,000 users (as of 18 March 2020) including lecturers and students to this online platform. As a measure to ensure that both teachers and students use the LMS, UEW has discouraged lecturers from holding classes on alternative learning platforms like the Telegram, Zoom, Google Classroom, among others. These initiatives reinforce the premium placed on online learning and for that matter, LMS by UEW in the face of the COVID-19 pandemic.

Studies have documented that online learning is one of the surest ways to mitigate the impact of COVID-19 on education. For instance, in his assessment of the impact of COVID-19 on education, Gyamerah (2020) recounted that effective online-learning could minimize the disruptions to the academic calendar and impact on girl-child education. Kituyi and Tusubira (2013) argued that compelling forces such as globalization, technological advancement and demographic forces drive the interest in integrating e-learning platforms in teaching environments is becoming more popular in higher learning institutions. In essence, education stakeholders have considered the call for the use of the elearning platform is seen as non-negotiable and a significant factor.

However, empirical studies have revealed that the use of e-learning is not immune to challenges. Studies have affirmed that creating remote classrooms can sometimes be problematic for parents, teachers and students (Lwoga, 2012; Ssekakubo, Suleman, \& Marsden, 2011; Tedre, Ngumbuke \& Kemppainen, 2010). As a result, researchers have investigated factors that either induce students' successful usage or throttle their desire to use online learning platforms. These included low internet bandwidth, lack of access to computers, poor ICT infrastructure and poor ICT support services. Teachers, on their part, blame the low patronage of e-Learning on lack of support and incentives from their institutions (Seaman, 2009). These scholars further adduced these factors to be responsible for the low patronage of e-Learning platforms. Gyamerah (2020) observed that many students in Ghana do not participate in e-Learning programmes because of the lack of access to internet services, power supply and digital devices like computers, smartphones and tablets. Gyamerah therefore notes that many students from underprivileged and under-resourced backgrounds are left behind their peers who have access to digital resources or peers who can receive adequate parental IT learning support. The proceeding discussion suggests that many factors influence the successful implementation of eLearning programmes and platforms. Even so, Gyamerah anticipated that the impact of COVID-19 would be critical on education, for countries with low economic resilience, poor technological infrastructure, inadequate education budgets, and high dropout rates. These bring into question the effectiveness of eLearning platforms such as the UEW-LMS. Therefore, for a successful implementation of the UEW-LMS, factors that induce or arouse users' interest and their challenges thereof must be unpacked. 
Extant literature reveals that one surest way of assessing the effectiveness of eLearning Platforms is by the analysis of its Strength, weakness, opportunities and threats. According to Hightower, Murphrey, Coppernoll, Jahedkar and Dooley (2011), a SWOT analysis relates to an in-depth, concurrent study of both the internal strengths, weaknesses, and the external opportunities and threats that may affect the success of a system positively or negatively. As a simple but potent tool, SWOT analysis is used for sizing up an organization's resource capability and deficiencies, its market opportunities, and the external threats to its future (Thompson, Strickland \& Gamble, 2006). In addition, studies have recognized that when internal factors such as strengths and weaknesses and external factors such as opportunities and threats are identified, could lead to the development of strategies which could lead to improvement in the strengths, elimination of the weaknesses, benefitting from of the opportunities and managing the threats (Parker, Maor, \& Herrington, 2013; Dyson, 2004).

In a study assessing blended learning, Ali, Buruga and Habibu (2019) did a SWOT analysis in public universities in Uganda, and reported that the blended learning had strengths in serving multiple students in a short duration, university preparation, connecting students both in and out of class, using basic skills IT and commitment from top management. Weaknesses identified from the study comprised unreliable internet, low/inadequate bandwidth, lack of plagiarism methods, scarce numbers of computers and poor internet access. Additionally, Opportunities reported included competency-based systems that made monitoring of individual development with respect to the university plans concerning growth easy, ensuring accessibility to way of learning regardless of location and the availability of external support. Finally, threats identified were irregular internet connections, erratic power supply, sharing students' credential for accessing the internet and the use of internet slangs and shorthands in writing student assignments. By this finding, we are inclined to believe that the users of UEW-LMS are likely to encounter similar experiences, albeit no evidence is available to support this claim. This study, therefore, was carried out to gather empirical proofs by identifying the SWOT of using the e-Learning Platform, UEW-LMS, at the University of Education Winneba.

\section{Statement of the Problem}

The use of Learning Management Systems (LMS) is not new to tertiary institutions in Ghana. Bervell and Umar (2017) opine that LMS has been in existence in tertiary institutions in Sub-Saharan Africa since the last decade. Various studies (Elmahadi \& Osman 2013; Mtebe \& Raisamo, 2014) further indicate that countries such as Kenya, Tanzania, Uganda, Ghana, Nigeria, South Africa among others have either fully or partially deployed LMS in various institutions in their countries as alternative or complementary to conventional classrooms. To further show the place of LMS in the development of tertiary education in Africa, Adkins (2013) predicted the growth rate of the LMS acquisition in Sub-Saharan Africa between 2011 and 2016 to rise by 5\% per annum. 
Despite the immense benefits of LMS in educational delivery, its usage in UEW has been very limited until the outbreak of the COVID-19 pandemic and the subsequent closure of schools on 16 Marc, 2020. As a new tool in the delivery of education in UEW, studies have not been conducted to ascertain the Strength, weaknesses, opportunities and threats from the perspectives of its users (students, lecturers and management). A study of this nature is very crucial because findings from extant literature seem inconclusive as far as the acceptance and rejection rate of LMS is concerned (Bervell \& Umar, 2017). For example, Sun, Tsai, Finger, Chen and Yeh (2008) as well as Hastie, Hung, Chen and Kinshuk (2010) confirm that there are some features in LMS that promote its acceptance rates.

On the other hand, Alkins, Coskuncay and Yildrim (2014) also report that many researchers have found that LMS has been rejected due to some failures. Apart from the dearth of literature concerning Strength, weaknesses, opportunities and threats from the perspectives of its users, a meta-review by Bervell and Umar (2017) revealed that out of the 31 studies conducted on the subject matter in SubSaharan Africa, only three (Lwoga \& Komba, 2015; Dlalisa, 2017; Tibyampansha et al., 2017) employed the mixed method approach whilst all the studies used the Technology Acceptance Model as a theoretical basis. Though six (Tagoe, 2012; Adjin-Tettey, 2014; Boateng, Mbrokoh, Boateng, Senyo \& Ansong, 2016; Essel \& Wilson, 2017; Okantey \& Addo, 2016; Asampana, Akanferi \& Ami-Narh, 2017) out of these 31 studies were conducted in Ghana, none of these studies was conducted in UEW amid a pandemic. Given the inherent lacuna in the literature, this mixed-method study was conducted using the Technology Acceptance Model as a model to fill the identified gaps.

\section{Research Questions}

1. What are users' perceptions of the strengths, weaknesses, opportunities, and threats of the UEW LMS?

2. What significant difference exists in the UEW LMS users' perception of the strengths, weaknesses, opportunities, and threats in terms of their gender?

3. What significant difference exists in the UEW LMS users' perception of the strengths, weaknesses, opportunities, and threats in terms of their age?

\section{Theoretical Framework: Technology Acceptance Model (TAM)}

The study was situated in the Technology Acceptance Model (TAM) developed by Davis (1989) and further refined by McFarland and Hamilton (2006). A pictorial presentation of TAM is presented in Figure 1. 


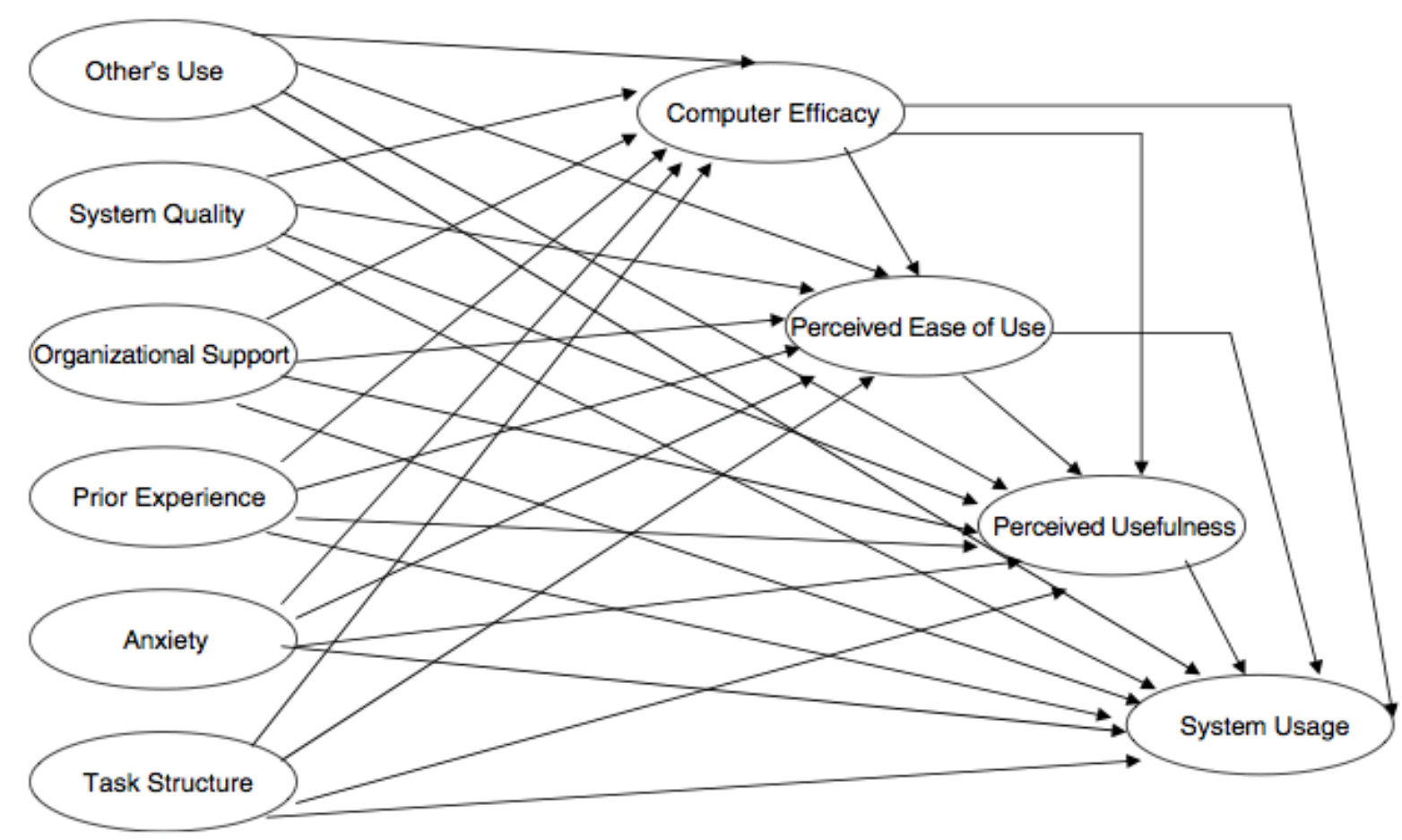

Figure 1: Adding contextual specificity to the Technology Acceptance Model from McFarland and Hamilton (2006)

The model remains one of the blueprints for testing user perceptions of a technological innovation globally. The model operates on the assumptions that an individual's intent to use (acceptance of innovation) and usage behaviour (actual use) of technology is influenced primarily by the individual's perceptions of ease of use and usefulness (benefits of using the technology) and computer efficacy (Portz et al., 2019) as evident from Figure 1, conditions such as task structure, anxiety, prior experience, organizational support, system quality and other's use determine their perception of usefulness and ease of use. However, the actual usage of technological innovation is further predicated on computer efficacy, perceived ease of use, and perceived usefulness. Thus, an individual who has control over the use of technology and finds it useful would be motivated to use the technology more often than an individual who finds it difficult to use technology or does not find it useful (Bandura, 1982).

As a theoretical lens for this study, it is argued that the actual use of the LMS is based on the user's perception of the strengths, weaknesses, opportunities, and threats. This means that the users are likely to accept and use the LMS when they realize its strengths and opportunities overrides its weaknesses and threats and vice versa. However, literature has shown that the users' perceptions of the LMS can be predicted by their gender, age, level of study, and faculty. It is envisaged that both males and females may differ in terms of their perceptions of the strengths, weaknesses, opportunities and threats. Extant literature suggests that the acceptance of technology depends on gender with males mostly dominating the acceptance of technology (Zhang, Nyheim \& Mattila, 2014). As far as age is concerned, research (Wang, Myers \& Sunduram, 2013) has 
shown that 'digital natives' are technology savvy. Impliedly, their acceptance of technology is expected to be higher compared to the digital 'immigrants'. Though the literature on how students' level of study as well as faculty attached might predict their perception of strengths, weaknesses, opportunities and threats, it is assumed that the more advanced students and students from the science-related faculties may tend to exhibit favourable responses than their colleagues from the humanities.

\section{Methodology \\ Research Design}

The study adopted the pragmatist research paradigm, a mixed-methods approach where both quantitative, as well as qualitative data, were collected. Specifically, the study employed the explanatory sequential design. The quantitative data was first collected and analyzed, and subsequently, qualitative data was collected and analyzed to help explain the quantitative results.

\section{Population}

The target population for the study was all students and lecturers at the University of Education, Winneba. The accessible population of 35200 comprising 34,680 regular students and 520 full-time lecturers on the Winneba campus (Admission Office and Human Resource Division, 2020).

\section{Sample and Sampling Procedures}

In this study, 3272 students were sampled for the quantitative phase. Bartlett, Kotrlik and Higgins (2001) recommend a sample size of 397 for a population of about 40,000. To increase the external validity of the findings, the researchers increased the sample to 3272. Again, the researchers increased the sample size with the view that a reduction in the return rate of the questionnaire might not affect the sample size and consequently, the results. The stratified random sampling technique was applied to sample from their gender, age, level of study and the faculties they represented. Based on Guest, Bunce, and Johnson's (2006) assertion that a minimum of 15 participants is enough for a qualitative study to reach saturation, 20 lecturers were sampled purposively for the interview.

\section{Data Collection Instrument}

A researcher-designed Likert-type questionnaire and semi-structured interview guide were used to gather data from the respondents. To ensure the questionnaire was valid, it was given to an expert to check for double, confusing, and leading questions. It was the pilot tested among 100 students in the University of Cape Coast who share similar characteristics to the respondents involved in the study. The pilot test yielded a reliability coefficient of 0.85 . The semi-structured interview guide was designed based on the findings that emerged from the quantitative analysis. The trustworthiness of the semistructured interview guide was determined through checking for credibility, transferability, dependability and confirmability as proposed by Lincoln and Guba (1985). 


\section{Data Collection Procedures}

The administration of the questionnaire was done from March 2020 to April 2020. At this period, the COVID-19 was at its peak in Ghana. As a result, a digital version of the questionnaire was created using Google Forms and used to collect data from the students. The digital form (online survey) of the questionnaire was administered first (by the researchers) and collected instantly through the digital mode. Subsequently, a semi-structured interview guide was designed based on the findings of the quantitative data to collect in-depth data explanation from the lecturers to triangulate the quantitative results.

\section{Data Analysis}

Data was analyzed using descriptive (Means and Standard Deviations) and Inferential Statistics (Independent Samples t-test and ANOVA) with the SPSS software. In the second stage, the researchers studied the field notes, transcribed the audio interview data, and analyzed them into themes based on the framework for thematic analysis suggested by Miles and Huberman (1994).

\section{Results and Discussions}

The demographic characteristics of the respondents are presented. This is followed by data analysis and discussion of findings.

\section{Demographic Characteristics of Respondents}

The demographic characteristics of the students are presented in Table 1.

Table 1: Demographic Characteristics of Respondents

\begin{tabular}{llcc}
\hline Variable & Sub-scale & Frequency & Percent \\
\hline Sex & Male & 1807 & 55.2 \\
& Female & 1465 & 44.8 \\
Age & Under 20 & 159 & 4.9 \\
& $20-29$ & 3081 & 94.2 \\
& $30-39$ & 5 & .2 \\
& $40+$ & 27 & .8 \\
\hline
\end{tabular}

Source: Online Survey Data, 2020

Table 1 shows that $1807(55.2 \%)$ of the respondents were males whilst 1465 $(44.8 \%)$ were females. The male dominance in the study only reinforces the longheld notion that most tertiary institutions in Africa especially admit more males than females (Fredua-Kwarteng \& Effah, 2017; Odaga, 2020). As for ages, Table 1 shows that that $159(4.9 \%)$ were below 20 years, 3081(94.2\%) were between 20 30 years, $5(.2 \%)$ were between $30-39$ years whilst $27.8 \%)$ were either 40 years or above. It is clear from their age distribution that about $99.0 \%$ of the respondents are digital 'natives' (Prensky, 2001). It is, therefore, expected that majority would accept the LMS. The age distribution may also affect their perceptions of the Strength, weaknesses, opportunities, and threats to the LMS.

Research Question One: What are the users' perceptions of the strengths, weaknesses, opportunities, and threats of the UEW LMS?

This research question aimed to investigate the perception of users of UEW-LMS on the strengths, weaknesses, opportunities, and threats of UEW-LMS. The data 
from the five-point Likert scale was analysed using means and standard deviation where a mean of 3.50 and above indicated the agreement of the respondents to the statement. A mean between 2.40 and 3.40 meant that the respondents were not certain of the statement whilst a mean below 2.40 meant the respondents disagreed with the statement. The results of the analysis have been presented in Table 2 .

Table 2: Summary of Students' Perception of UEW-LMS

\begin{tabular}{lccll}
\hline SWOT Analysis & Min. & Max. & Mean & Std. Deviation \\
\hline Weakness & 1 & 5 & 3.85 & 0.66 \\
Threats & 1 & 5 & 3.82 & 0.56 \\
Strengths & 1 & 5 & 2.80 & 0.83 \\
Opportunities & 1 & 5 & 2.57 & 0.93 \\
Overall SWOT Analysis & 1 & 5 & 3.37 & 0.43 \\
\hline
\end{tabular}

Source: Online Survey Data, 2020

The data in Table 2 reveal that users' of UEW-LMS held varied perceptions about the strengths, weaknesses, opportunities, and threats of UEW-LMS outlined in this study. However, ranked by means, it could be observed that users' of UEW-LMS have higher perceptions about the weakness $(\mathrm{M}=3.85$, $\mathrm{SD}=0.66)$ followed by threats $(\mathrm{M}=3.82, \mathrm{SD}=0.56)$, strengths $(\mathrm{M}=2.80, \mathrm{SD}=0.83)$ whiles opportunities $(\mathrm{M}=2.57, \mathrm{SD}=0.93)$ was rated the least. The overall assessment of the strengths, weaknesses, opportunities and threats of UEW-LMS returned a mean of $3.37(\mathrm{SD}=0.43)$. Based on the 5-point Likert scale used for the data where the mean/average is 3.0, it could be noticed that the users' perceptions of UEW-LMS on the SWOT scored above average. Impliedly, UEWLMS has an element of strengths, weaknesses, opportunities and threats. A detailed description of the student's perspectives on the strengths, weaknesses, opportunities and threats of UEW's LMS is presented in Table 3.

Table 3: Detailed SWOT Analysis of UEW-LMS from the Students Perspectives

\begin{tabular}{|c|c|c|c|c|c|}
\hline Constructs & Items & Min. & Max. & Mean & $\begin{array}{l}\text { Std. } \\
\text { Dev. }\end{array}$ \\
\hline & Improves IT Skills & 1 & 5 & 3.39 & 1.19 \\
\hline \multirow[t]{7}{*}{ Strengths } & Students complete tasks at their own pace & 1 & 5 & 3.15 & 1.23 \\
\hline & Univ Commitment & 1 & 5 & 2.96 & 1.30 \\
\hline & Instant Results & 1 & 5 & 2.95 & 1.31 \\
\hline & Access to learning materials & 1 & 5 & 2.79 & 1.21 \\
\hline & $\begin{array}{l}\text { Students can learn irrespective of their } \\
\text { location }\end{array}$ & 1 & 5 & 2.56 & 1.28 \\
\hline & Serves Large numbers & 1 & 5 & 2.36 & 1.25 \\
\hline & No data cost & 1 & 5 & 2.21 & 1.30 \\
\hline \multirow[t]{5}{*}{ Weakness } & Persons with limited ICT & 1 & 5 & 4.45 & 0.89 \\
\hline & Time restrictions & 1 & 5 & 4.39 & 0.93 \\
\hline & Login and enrollment complicated & 1 & 5 & 3.80 & 1.26 \\
\hline & No App version & 1 & 5 & 3.72 & 1.19 \\
\hline & Interface no attractive & 1 & 5 & 3.35 & 1.23 \\
\hline Opportunities & Students can go over lessons severally & 1 & 5 & 2.87 & 1.28 \\
\hline
\end{tabular}




\begin{tabular}{llllll}
\hline & Make education accessible to more students & 1 & 5 & 2.82 & 1.33 \\
& $\begin{array}{l}\text { Easier to plan and manage to learn } \\
\text { It better serves the needs physically }\end{array}$ & 1 & 5 & 2.53 & 1.24 \\
challenged persons & 1 & 5 & 2.37 & 1.31 \\
Means of learning regardless of location & 1 & 5 & 2.27 & 1.30 \\
Threats & 1 & 5 & 3.40 & 1.12 \\
& $\begin{array}{l}\text { Plagiarism (copy work) } \\
\text { Lack of computers }\end{array}$ & 1 & 5 & 4.39 & 0.93 \\
Insufficient training & 1 & 5 & 4.28 & 0.95 \\
Size of files & 1 & 5 & 4.17 & 1.02 \\
No video-conferencing & 1 & 5 & 4.15 & 0.98 \\
It is expensive to use LMS & 1 & 5 & 4.03 & 1.21 \\
Unstable power supply & 1 & 5 & 3.98 & 1.12 \\
Limited competencies in ICT & 1 & 5 & 3.89 & 1.10 \\
Lack of commitment & 1 & 5 & 3.30 & 1.34 \\
Resistance to adopting change & 1 & 5 & 3.29 & 1.35 \\
May deteriorate students' language & 1 & 5 & 3.26 & 1.24 \\
Exchange of username and passwords & 1 & 5 & 3.22 & 1.32 \\
Distractions & 1 & 5 & 3.16 & 1.18 \\
\hline
\end{tabular}

Source: Field Data, 2020

Even though the Overall SWOT analysis presented a Mean $=3.37$ and an Average $\mathrm{SD}=.43$, a cursory look at the details in Table 3 shows that the students expressed various perceptions on the Strength, weaknesses, opportunities, and threats about UEW LMS. Concerning the Strength of the LMS, an Overall Mean of 2.8 and an Average Deviation of .83 was obtained. This implies that their overall perception of the Strength was moderate. It was, therefore, not surprising that the students agreed (Mean $=3.9, \mathrm{SD}=1.19$ ) that LMS improves their Information Technology skills. The constant use of an innovation is expected to sharpen the user's skill. Paul (2014) is of the view that the constant use of technology has a multiplier effect on the computer skills of the user. The more the user uses the innovation, the more he becomes adept in its usage. This perception of the students was concurred by the lecturers in the interview. For some of the lecturers even though they had always considered themselves as beginners in the use of technology, they now see themselves at the advanced stage due to the constant usage of the LMS for the teaching and learning activities. One of the lecturers said:

"Until this Covid-19 period and the subsequent introduction of LMS in our classroom domains, I have not been this conversant with the laptop and its associated applications." (Participant C)

Another lecturer who shared a similar sentiment remarked:

"For me, the LMS has been a blessing. At the initial stages, when we were asked to teach on the LMS, I struggled due to my limited knowledge and skill in the use of a computer. But now, I can proudly say I do everything on the LMS without external support." (Participant B)

It is, therefore, evident that the shift in pedagogical practice from the face-to-face to LMS has enhanced the computer skills of both lecturers and students. This finding is consistent with that of Gunawan, Sahidu, Susilawati, Harjono, and Herayanti (2019) who found that the use of MOODLE over a period enhanced 
the skills and creativity of its users. It is believed that once a user has the skill and dexterity to surf LMS independently, they can manage their lessons at their own pace. As data in Table 3 reveals, the students agreed (Mean $=3.5, \mathrm{SD}=1.23$ ) that they can learn at their own pace on the LMS. Comparatively, the LMS allows students to decide when and where they want to have their lessons, unlike the traditional face-to-face classrooms where students' learning is mostly managed by teachers. Umek, Kerzic, Tomazevic and Aristovnik (2015) posit that the use of LMS requires students who are highly self-regulated and independent to manage their lessons. It also stands to reason, therefore, that the performance of the students on the LMS rests mainly on their ability to manage their learning effectively. In the interview with the lecturers, it came to the fore that management of the students learning is their inalienable right. Should they decide not to learn, their teachers have little control, unlike the traditional faceto-face classroom. For example, one lecturer said:

"Once I upload my materials on the platform, I do not check how many students have accessed it or otherwise. If it were the traditional classroom, the onus would lie on me to ensure that every student has accessed the materials." (Participant E)

Another lecturer also said:

"I upload the information on the LMS and allow the students to access whenever they want to. I don't indicate when they should. It depends on the individual student." (Participant C)

This confirms the findings of Pelet (2013) that the LMS provides the avenue for students to manage their learning. This would give students more control over what they want to learn at their own pace.

Interestingly, the students did not agree that there is no financial cost (Mean = $2.21, \mathrm{SD}=1.25$ ) as well as LMS serving a large number of users at a time. Though the UEW has established collaboration with two telecommunication networks (MTN and Vodafone) to whitelist the UEW LMS website, it appears the students did not seem to know about it and perceive not to be benefitting from this arrangement. It seems to suggest that students cannot access the LMS portal once they do not have an internet connection at all. Unsurprisingly, the students identified expensive internet bandwidth, unstable internet (Mean = $4.62, \mathrm{SD}=.84$ ) and lack of computers (Mean $=4.39, \mathrm{SD}=.93$ ) as the threats to their use of LMS. This further explains why the students indicated that LMS does not serve a large number of people. Internet demands, as well as the nonuse of computers and smartphones by students, are likely to reduce the number of students who access LMS. Most lecturers supported the views of the students during the interview. For instance, one of the lecturers said:

"Most of my students complain to me that though they want to enrol in the LMS, they do not have either smartphones or data to access the LMS. Though the school says students can browse freely, my students are still complaining." (Participant A) 
Another lecturer also remarked:

"The issue of data is not only affecting the students but even we as lecturers. Though the system, we are told, is free, I always have to bundle on my phone before I can access the platform." (Participant G)

To other lecturers, however, the problems are quite expansive than they are presumed. Most of the students in UEW come from the remotest part of Ghana with internet connectivity in these areas remaining significantly poor, coupled with the problems of unreliable electricity supply. This makes it difficult for the students to access the LMS from their homes. Even when students can connect their phones and computers to the internet, the internet speed remains discouraging. Most of the students have to commute several miles to gain access to the internet. One lecturer lamented:

"You have no idea where some of these students are coming from. Some of them come from villages that have no internet or electricity." (Participant I)

Another lecturer supported this assertion from his colleague by saying that:

"Though the LMS is good, most of my students come from remote parts of the country. Some of them have to travel several miles just to charge their mobile phones and connect to the internet." (Participant B)

Even though Ghana's internet connectivity remains one of the best in Africa, Akakpo (2008) indicates that accessibility remains discouraging for most rural communities in Ghana. The lack of internet infrastructure in most villages may not allow the students from these parts of the country to enrol in the LMS. Apuke and Iyendo (2018) posit that learning management systems were generally designed to support students in their learning, lack of available technologies as well as data cost may deprive most users of the full benefits of these systems. This is quite expected because Gyamerah (2020) had earlier predicted that in Ghana many students might not take part in classes on Moodle platforms due to inaccessibility to internet, electricity and digital devices such as smartphones, tablets and computers. However, an App version of the LMS could have made it more user friendly for students, many of whom use smartphones instead of computers. It is not surprising that the students agreed $(\mathrm{M}=3.72, \mathrm{SD}=1.19)$ that no App version of the LMS remains one of its biggest challenges.

From Table 3, it is evident that UEW LMS has a number of weaknesses. According to the students, it is difficult for persons with limited knowledge in ICT $(\mathrm{M}=4.45, \mathrm{SD}=.89)$ to use the LMS. Arguably, people who possess the efficacy in the use of technology would be inclined to use the LMS than persons with limited knowledge in ICT. As found by Nasser, Cherif, and Romanoski (2011), there is a strong correlation between students' knowledge of ICT and the use of LMS. It is, therefore, that most students might not use the LMS for the purpose that is intended due to limited knowledge in ICT. The novelty of the LMS in the educational landscape of UEW further presupposes that it may take a lot of time before users become conversant with the platform. Students' lack of 
knowledge in the use of ICT was further reinforced by the lecturers who mostly have to offer support to these students. One lecturer, for instance, said:

"I have enrolled more than 500 of my students on the LMS manually. Besides, I have to always be on standby to give further instructions and tutorials on how the students can navigate the LMS." (Participant B)

Another lecturer also posited:

"My students have been complaining bitterly about how the LMS is working. I think they don't have adequate knowledge of the use of ICT." (Participant H)

Amid the students' lack of knowledge in the use of ICT, it was not surprising that the students agreed to have login and enrolment complications (Mean 3.80, $\mathrm{SD}=1.26$ ). The novelty of LMS, coupled with the huge number of students that were migrated unto the LMS platform, was expected to affect the performance rate of the server. With the outbreak of the pandemic, all courses were switched online. As a result, the computer servers were not able to host a large scale of new users forcing the online system too often slow or shut down completely (Bao, 2020). Irrespective, the majority of the users could not log in or had enrolment complications as a result of inadequate training. Most of the lecturers interviewed complained that even though they were given some form of training, it was self-tutoring without many practical activities for participants except videos and excerpts from Youtube. For example, one lecturer complained:

"You see, I understand why the students are complaining about the LMS, even me, that three times training they did on the LMS did not equip me with all the skills I needed to use the LMS, how much more a student who has not even heard of LMS before?" (Participant A)

This argument from the lecturer's comment suggests that the users would have wished to have more training and orientation before the LMS was implemented on that large scale. Predictably, the students identified insufficient training (Mean $=4.28, \mathrm{SD}=.95)$ as the third-highest perceived threat to the use of LMS. Habibu, Al-Mamun and Clement (2012) are of the view that lack of proper training skills on the use of online learning platforms in most tertiary institutions is a challenge for both teachers and students. Narh, Boateng, Afful-Dadzie and Owusu (2019) found that most students in Ghana have poor computer skills and self-efficacy and inadequate knowledge of internet handles. The results show further show that the students agreed that plagiarism $(\mathrm{M}=3.40, \mathrm{SD}=1.12)$ is another weakness of the LMS. Research (King, Guyette, \& Piotrowski, 2009) has shown that it is easier for students to cheat or plagiarize in online-class than in traditional classes. It is argued that the nature of LMS and other learning management platforms afford students the luxury of using other people's ideas or information without acknowledging the person as the source. The nature of LMS does not present lecturers with the option to test the assignments presented by students. This is as a result of the lack of in-built capacity to test for the authenticity or originality of the information presented by students. As indicated by Michael and Williams (2013), in a traditional classroom, it is easy for administrators of a test to control cheating behaviours such us copying from 
a neighbour, taking copies or photos of the exam out of the classroom, or students working to together in other ways unlike in an online platform where students may plagiarize or many students presenting the same write-up in a course.

As far as the opportunities are concerned, the students agreed that LMS allows students to go over lessons severally (Mean $=2.87, \mathrm{SD}=1.27$ ). Once the slides are uploaded on the LMS, the students have access to the slides anytime they want. This approach from the perspective of the students allows them to go over lessons at convenient times than they could have done in traditional classrooms. Lim (2004) maintains that the mode of teaching online enables students to control their learning path, pace, sequence and contingencies. It was therefore not surprising that the students agreed that it is easier for them to plan and manage their leaning on the LMS (Mean $=2.53, \mathrm{SD}=1.24$ ). Again, the findings in Table reveals that LMS would make education accessible to more students (Mean $=2.82, \mathrm{SD}=1.33$ ). With the completion of the first batch of the Free Senior High School in Ghana, it is envisaged that the LMS provides a complete avenue for educational enrolment in tertiary to be expanded. Though in the traditional face-to-face teaching, facial expressions, body language as well as the voices of teachers and peers affect the comprehension and formative evaluation of the students (Bao, 2020), a blended pedagogy could enable UEW to expand its admission capacity. Pirani and Sasikumar (2014) posit that the elastic nature of LMS makes it ideal for any type of educational structure. It is, therefore, assumed that the LMS would make education accessible to both the abled and the disabled. Howard, Winkelmes and Shegog (2018) concur with this finding by intimating that the goal of every virtual classroom is to improve access to higher education. Indeed, the lecturers supported the views of the students. For instance, one lecturer posited:

"With the upsurge in the number of people seeking tertiary education next year, I think LMS remains the best platform to make education accessible to these students." (Participant D)

Another lecturer also remarked:

"I think the LMS has come at a good time. This is an opportunity for UEW to expand its admission capacity for every student that wants to come." (Participant F)

LMS would give management of UEW the opportunity to expand its accessibility rates, especially for students with disabilities, rural students, students with parental responsibilities, and students in the security services (Renes, 2015).

Furthermore, the students agreed (Mean $=4.17, \mathrm{SD}=1.02$ ) that the size of files that can be uploaded on the LMS is a threat. Currently, the size of files that a user can upload on the LMS is 50megabites. Most users often have to alter the size of their videos and other audio materials in other for it to suit the architectural design of the LMS platform, thereby, reducing the quality of video or audio material. Besides, apart from MPEG-4 (.mp4) and JPEG, the LMS does not support other video formats such Audio Video Interleave (.avi), Windows 
Media Video (.wmv), Flash (.flv or .swf) and QuickTime (.mov). It is argued, therefore, that most videos that are uploaded on the LMS lose its quality due to the limited formats that users have to adopt. The interview with the lecturers confirmed that the limited file size, as well as the file format, often affects the quality of the materials that are uploaded on the LMS. For instance, one lecturer said:

"I think the size of files that can be uploaded on the LMS is too small for some of us from the School of Creative Arts where students are required to mostly present their assignments in videos." (Participant G)

Another lecturer from a different department commented:

"I have to mostly alter the videos I upload on the LMS for my students either by reducing the size or the file format before I upload it. This mostly affects the content as well as the quality of the video." (Participant D)

Apart from this, a lecturer from the Special Education Department also revealed that not the videos and audio files suit all students in the classroom. Some of the materials on the LMS are not operable to some of the students with disabilities. She said:

"Most of our students are not benefiting enough from the LMS. Enrolling on the platform, for example, it is a challenge for students with hearing and visual impairment. The whole interface is not user friendly for these categories of our students." (Participant E)

Even though the emergence of technology was expected to ameliorate the problem of disability, it has rather heightened the problem (Dobransky \& Hargittai, 2006). Arguably, online learning platforms such as the LMS have failed to address the technical and pedagogical aspects of accessibility and inclusion (Guglielman, 2010).

Research Question Two: What significant difference exists in the UEW LMS users' perception of the strengths, weaknesses, opportunities, and threats in terms of their gender?

Research question two sought to establish whether the users of LMS differ significantly in their perceptions of strengths, weaknesses, opportunities, and threats in terms of their gender. The t-test result is presented in Tables 3.

Table 3: T-test Results for Gender and SWOT of UEW-LMS

\begin{tabular}{llccccc}
\hline & Gender & Mean & Std. Deviation & $\mathrm{t}$ & $\mathrm{df}$ & $\begin{array}{c}\text { Sig. (2- } \\
\text { tailed) }\end{array}$ \\
\hline Strengths & Male & 2.80 & 0.85 & -0.030 & 3270 & 0.976 \\
& Female & 2.80 & 0.81 & & & \\
Weakness & Male & 3.85 & 0.67 & 0.184 & 3270 & 0.854 \\
& Female & 3.84 & 0.65 & & & \\
Opportunities & Male & 2.57 & 0.94 & -0.395 & 3270 & 0.693 \\
& Female & 2.58 & 0.91 & & & \\
Threats & Male & 3.82 & 0.57 & -0.759 & 3270 & 0.448 \\
& Female & 3.83 & 0.55 & & & \\
Overall SWOT & Male & 3.36 & 0.44 & -0.798 & 3270 & 0.425 \\
Analysis & Female & 3.38 & 0.41 & & & \\
\hline
\end{tabular}

Source: Online Survey Data, 2020 
Results in Table 4 show whether there is a statistically significant difference between the gender of students and their perceptions of strengths, weaknesses, opportunities, and threats of the LMS. It is clear from the independent samples ttest results in Table 4 that there were no statistically significant differences in the students perception in relation to the strengths $[\mathrm{t}(3270)=-0.030, \mathrm{p}=0.976,2$ tailed], weakness [ $\mathrm{t}(3270)=0.184, \mathrm{p}=0.854,2$-tailed], opportunities $\mathrm{t}(3270)=$ 0.395, $\mathrm{p}=0.693$, 2-tailed], threats $\mathrm{t}(3270)=-0.759, \mathrm{p}=0.448,2$-tailed], as well as the overall SWOT [ $\mathrm{t}(3270)=-0.798, \mathrm{p}=0.425,2$-tailed] based on gender at 0.05 alpha level. This means that both the men and women did not differ in terms of the perceptions of the strengths, weaknesses, opportunities, and threats of the LMS. This finding of this study is consistent with that of Srichanyachon (2014) and Arenas-Gaitan, Rondan-Cataluna and Ramirez-Correa (2010) who found that there was no statistically significant difference between the gender of the students and their perception towards the use of LMS.

Research Question Three: What significant difference exists in the UEW LMS users' perception of the strengths, weaknesses, opportunities, and threats in terms of their age?

To determine whether the users of LMS differ in terms of the strengths, weaknesses, opportunities, and threats based on the age of the users. An ANOVA was conducted. The result is displayed in Table 5.

Table 5: ANOVA Results for Age and SWOT Perception of UEW-LMS

\begin{tabular}{|c|c|c|c|c|c|c|c|c|}
\hline & Age & Mean & $\begin{array}{l}\text { Std. } \\
\text { Dev. }\end{array}$ & $\begin{array}{c}\text { Sum of } \\
\text { Squares }\end{array}$ & $\mathrm{df}$ & $\begin{array}{l}\text { Mean } \\
\text { Square }\end{array}$ & $\mathrm{F}$ & Sig. \\
\hline \multirow[t]{7}{*}{ Strengths } & $\begin{array}{l}\text { Under } \\
20\end{array}$ & 2.83 & 0.82 & 8.274 & 3 & 2.758 & 3.989 & 0.008 \\
\hline & $20-29$ & 2.79 & 0.83 & 2239.563 & 3269 & 0.691 & & \\
\hline & $30-39$ & 1.81 & 0.72 & & & & & \\
\hline & $40+$ & 3.19 & 0.89 & & & & & \\
\hline & Total & 2.80 & 0.83 & & & & & \\
\hline & Under & 3.78 & 0.57 & & & & & \\
\hline & 20 & & & & & & & \\
\hline \multirow[t]{6}{*}{ Weakness } & $20-29$ & 3.85 & 0.66 & 6.096 & 3 & 2.032 & 4.687 & 0.003 \\
\hline & 30-39 & 2.92 & 1.28 & 1390.620 & 3269 & 0.433 & & \\
\hline & $40+$ & 3.59 & 0.65 & & & & & \\
\hline & Total & 3.85 & 0.66 & & & & & \\
\hline & Under & 2.67 & 0.87 & & & & & \\
\hline & 20 & & & & & & & \\
\hline \multirow[t]{6}{*}{ Opportunities } & $20-29$ & 2.57 & 0.93 & 2.625 & 3 & 0.875 & 1.021 & 0.382 \\
\hline & 30-39 & 2.47 & 0.23 & 2724.987 & 3269 & 0.857 & & \\
\hline & $40+$ & 2.78 & 0.96 & & & & & \\
\hline & Total & 2.57 & 0.93 & & & & & \\
\hline & Under & 3.80 & 0.55 & & & & & \\
\hline & 20 & & & & & & & \\
\hline \multirow[t]{5}{*}{ Threats } & $20-29$ & 3.83 & 0.56 & 1.767 & 3 & 0.589 & 1.878 & 0.131 \\
\hline & 30-39 & 4.03 & 0.36 & 1010.289 & 3269 & 0.314 & & \\
\hline & $40+$ & 3.59 & 0.66 & & & & & \\
\hline & Total & 3.82 & 0.56 & & & & & \\
\hline & Under & 3.35 & 0.44 & & & & & \\
\hline
\end{tabular}




\begin{tabular}{llllccccc}
\hline & 20 & & & & & & & \\
Overall & $20-29$ & 3.37 & 0.42 & 2.073 & 3 & 0.691 & 3.831 & 0.009 \\
SWOT & $30-39$ & 2.66 & 1.10 & 585.412 & 3269 & 0.180 & & \\
Analysis & $40+$ & 3.36 & 0.45 & & & & & \\
& Total & 3.37 & 0.43 & & & & & \\
& & & & & & & & \\
\end{tabular}

Source: Online Survey Data, 2020

It is evident in Table 5 that except for opportunities $[\mathrm{F}(3,3269)=1.021, \mathrm{p}=0.382]$, and threats $[\mathrm{F}(3,3269)=1.878, \mathrm{p}=0.131]$, where there were no statistically significant differences, there were statistically significant differences in the perception of UEW students' concerning strengths $[\mathrm{F}(3,3269)=3.989, \mathrm{p}=0.008]$, weakness $[\mathrm{F}(3,3269)=4.687, \mathrm{p}=0.003]$, as well as the overall SWOT analysis [F $(3,3269)=3.831, p=0.009$ ] at 0.05 alpha level across the age groups. Based on these results, it could be concluded that people of different age groups may not formulate the same perceptions towards the various elements of the LMS. Extant literature (Lim, Ayesh \& Chee, 2013) suggest that even though the users of LMS are provided with the same elements on the LMS, not all of them may have the same perception of tolerance level to surf the internet to their satisfaction. As a result, different age groups may exhibit different perceptions towards the strengths, weaknesses, opportunities, and threats of the LMS.

\section{Conclusions and Recommendations for Policy and Practice}

The study investigated users' perceptions of UEW LMS based on Strength, weaknesses, opportunities, and threats. The study found that UEW LMS is perceived to have elements of weaknesses, threats, strengths and opportunities. The study further found that the users of LMS differ in their perceptions of the strengths, weaknesses, opportunities, and threats based on the age of the students. The users, however, did not differ significantly in their perceptions of the strengths, weaknesses, opportunities, and threats based on gender. It is clear from the findings that most of the users of LMS do not see the relevance or have not bought into the use of LMS. Based on the findings of the study, we concluded that most of the users of UEW LMS might not continue to use the platform for their teaching and learning activities after COVID-19 and that the usage of LMS would become abortive whenever users have the opportunity to choose between the LMS and the traditional classroom approach to instruction.

To maintain and sustain the interest of the users on the LMS, it is recommended that Management of UEW LMS need to educate both lecturers and students about the benefits that LMS offers to its users. Such awareness programmes would offer the users the opportunity to understand the importance and benefits of LMS in the pedagogic practices of both students and lecturers in the modernday educational dispensation. Additionally, management needs to conduct comprehensive practical workshops and training for all users of the LMS to equip them with the knowledge and skills needed to use LMS. The Management of the University of Education, Winneba should take into consideration the age, level as well as the programme of study in the design and implementation of subsequent online platforms for students and lecturers. 


\section{References}

Adjin-Tettey, T. D. (2014). Adoption and utilization of learning/course management systems: The study of University of Professional Studies, Accra. International Journal of ICT and Management, 2(1), 48-64.

Admission Office and Human Resource Division. (2020). Students and lecturers' statistics 2020. Winneba: University of Education, Winneba

Adkins, S. S. (2013). The Africa market for self-paced e-learning products and services: Forecast and analysis. Retrieved from http://www.ambientinsight.com/Resources/Documents/AmbientInsight2011-2016-Africa-SelfPaced-eLearning-Market-Abstract.pdf

Akakpo, J. (2008). Rural Access: Options and challenges for connectivity and energy in Ghana. Accra: International Institute for Communication and Development (IICD) and the Ghana Information Network for Knowledge Sharing (GINKS).

Ali, G., Buruga, B. A., \& Habibu, T. (2019). SWOT analysis of blended learning in public universities of Uganda: A case study of muni university. JMultidisciplinary Scientific Journal, 2(4), 410-429. https://doi.org/10.3390/j20400 27

Alkis, N., Coskunçay, D. F., \& Yildirim, S. Ö. (2014, September). A systematic review of Technology Acceptance Model in e-learning context. In Proceedings of the XV International Conference on Human Computer Interaction, 55, 1-5. https://doi.org/10.1145/2662253.2662308

Apuke, O. D., \& Iyendo, T. O. (2018). University students' usage of the internet resources for research and learning: forms of access and perceptions of utility. Heliyon, 4(12), 1-34. https://doi.org/10.1016/j.heliyon.2018.e01052

Arenas-Gaitán, J., Rondan-Cataluña, F. J., \& Ramirez-Correa, P. E. (2010, November). Gender influence in perception and adoption of e-learning platforms. In Proceedings of the 9th WSEAS international conference on Data networks, communications, computers (pp. 30-35). World Scientific and Engineering Academy and Society (WSEAS)

Asampana, I., Akanferi, A. A., \& Ami-Narh, J. (2017). Reasons for poor acceptance of web-based learning using an LMS and VLE in Ghana. Interdisciplinary Journal of Information, Knowledge \& Management, 12, 189-208.

Bandura, A. (1982). Self-efficacy mechanism in human agency. American psychologist, 37(2), 122. https://doi.org/10.1037/0003-066X.37.2.122

Bao, W. (2020). COVID-19 and online teaching in higher education: A case study of Peking University. Human Behavior and Emerging Technologies, 2(2), 113-115. https://doi.org/10.1002/hbe2.191

Bartlett, J. E., Kotrlik, J. W., \& Higgins, C. C. (2001). Organizational research: Determining appropriate sample size in survey research. Information technology, learning, and performance journal, 19(1), 43-50.

Bervell, B., \& Umar, I. N. (2017). A decade of LMS acceptance and adoption research in Sub-Sahara African higher education: A systematic review of models, methodologies, milestones and main challenges. Eurasia Journal of Mathematics, Science and Technology Education, 13(11), 7269-7286. https://doi.org/10.12973/ejmste/79444

Boateng, R., Mbrokoh, A. S., Boateng, L., Senyo, P. K., \& Ansong, E. (2016). Determinants of e-learning adoption among students of developing countries. The International Journal of Information and Learning Technology, 33(4), 248-262. https:// doi.org/10.1108/IJILT-02-2016-0008

Davis, F. D. (1989). Perceived usefulness, perceived ease of use, and user acceptance of information technology. MIS quarterly, 319-340. 
Dlalisa, S. (2017, March). Acceptance and usage of learning management systems amongst academics. In 2017 Conference on Information Communication Technology and Society (ICTAS) (pp. https://doi.org/10.1109/ICTAS.2017.7920525

Dobransky, K., \& Hargittai, E. (2006). The disability divide in internet access and use. Information, Communication \& Society, 9(3), 313-334. https://doi.org/ 10.1080/13691180600751298.

Dyson, R. G. (2004). Strategic development and SWOT analysis at the University of Warwick. European journal of operational research,152(3), 631-640. https:// doi.org/10.1016/S0377-2217(03)00062-6

Elmahadi, I., \& Osman, I. (2013, May). A study of the Sudanese students' use of collaborative tools within Moodle Learning Management System. In 2013 ISTAfrica Conference $\mathcal{E}$ Exhibition (pp. 1-8). IEEE.

Essel, D. D., \& Wilson, O. A. (2017). Factors affecting university students' use of Moodle: An empirical study based on TAM. International Journal of Information and Communication Technology Education (IJICTE), 13(1), 14-26. https://doi.org/10.4018/IJICTE.2017010102.

Fredua-Kwarteng, E., \& Effah, C. (2017). Gender inequity in African university engineering programs. International Higher Education, (89), 18-19. http://dx.doi.org/10.6017/ihe.2017.89.9767

Gyamerah, K. (2020). Education and COVID-19: Is Ghana ready to return to the classroom? Retrieved from https://schoolofeducation.blogs.bristol.ac.uk/tag/covid-19.

Guest, G., Bunce, A., \& Johnson, L. (2006). How many interviews are enough? An experiment with data saturation and variability. Field methods, 18(1), 59-82. https://doi.org/10.1177/1525822X05279903

Guglielman, E. (2010). E-Learning and disability: Accessibility as a contributor to inclusion. Fifth Doctoral Consortium at the European Conference on Technology Enhanced Learning, Barcelona, Spain, 29 September, pp. 31-36.

Gunawan, G., Sahidu, H., Susilawati, S., Harjono, A., \& Herayanti, L. (2019, December). Learning Management System with Moodle to Enhance Creativity of Candidate Physics Teacher. In Journal of Physics: Conference Series, 1417(1), pp. 1-6. https://doi.org/10.1088/1742-6596/1417/1/012078

Hastie, M., Hung, I. C., \& Chen, N. S. Kinshuk (2010). A blended synchronous learning model for international educational collaboration. Innovations in Education and Teaching International, 1(47), 9-24. https:/ / doi.org/10.1080/14703290903525812

Habibu, T., Abdullah-Al-Mamun, M., \& Clement, C. (2012). Difficulties faced by teachers in using ICT in teaching-learning at technical and higher educational institutions of Uganda. International Journal of Engineering, 1(7), 1-10.

Hightower, T. E., Murphrey, T. P., Coppernoll, S. M., Jahedkar, J., \& Dooley, K. E. (2011). An examination of the strengths, weaknesses, opportunities, and threats associated with the adoption of Moodle ${ }^{\mathrm{TM}}$ by eXtension. Journal of Extension, 49(6).

King, C. G., Guyette Jr, R. W., \& Piotrowski, C. (2009). Online exams and cheating: An empirical analysis of business students' views. Journal of Educators Online, 6(1), 18.

Kituyi, G., \& Tusubira, I. (2013). A framework for the integration of e-learning in higher education institutions in developing countries. International Journal of Education and Development using ICT, 9(2), 19-36. 
Lim, D. H. (2004). The effect of flexible learning schedule on online learners' learning, application, and instructional perception. Online Submission. Retrieved from https://files.eric.ed.gov/fulltext/ED492499.pdf

Lim, Y. M., Ayesh, A., \& Chee, K. N. (2013). Socio-demographic differences in the perceptions of the learning management system (LMS) design. International Journal of Software Engineering \& Applications, 4(5), 15-35.

Lwoga, E. (2012). Making learning and Web 2.0 technologies work for higher learning institutions in Africa. Campus-Wide Information Systems, 29(2), 90-107. https://doi.org/10.1108/10650741211212359

Lincoln, Y. S., \& Guba, E. G. (1985). Naturalistic inquiry. Beverly Hills, CA: Sage Publications, Inc.

Lwoga, E. T., \& Komba, M. (2015). Antecedents of continued usage intentions of webbased learning management system in Tanzania. Education+ training, 57(7), 738756. https://doi.org/10.1108/ET-02-2014-0014

McFarland, D. J., \& Hamilton, D. (2006). Adding contextual specificity to the technology acceptance model. Computers in human behaviour, 22(3), 427-447. https:// doi.org/10.1016/j.chb.2004.09.009

Michael, T. B., \& Williams, M. A. (2013). Student equity: Discouraging cheating in online courses. Administrative Issues $\quad$ Journal, 3(2), https://doi.org/10.5929/2013.3.2.8

Miles, M. B., \& Huberman, A. M. (1994). Qualitative data analysis: An expanded sourcebook. London: Sage.

Mtebe, J. S., \& Raisamo, R. (2014). Investigating perceived barriers to the use of open educational resources in higher education in Tanzania. International Review of Research in Open and Distributed Learning, 15(2), 43-66. https://doi.org/10.19173/irrodl.v15i2.1803

Narh, N., Boateng, R., Afful-Dadzie, E., \& Owusu, A. (2019). Virtual platforms: Assessing the challenges of e-learning in Ghana. In Twenty-fifth Americas Conference on Information Systems, Cancun, 2019 (pp. 1-10).

Nasser, R., Cherif, M., \& Romanowski, M. (2011). Factors that impact student usage of the learning management system in Qatari schools. The International Review of Research in Open and Distributed Learning, 12(6), 39-62. https://doi.org/10.19173/irrodl.v12i6.985

Odaga, G. (2020). Gender in Uganda's tertiary educational distribution. Social Sciences $\mathcal{E}$ Humanities Open, 2(1), 100023. https://doi.org/10.1016/j.ssaho.2020.100023

Okantey, M., \& Addo, H. (2016). Effect of theoretical and institutional factors on the adoption of e-learning. European Scientific Journal, 12(16). https:// doi.org/10.19044/esj.2016.v12n16p475

Parker, J., Maor, D., \& Herrington, J. (2013). Authentic online learning: Aligning learner needs, pedagogy, and technology. Issues in Educational Research, 23(2), 227-241.

Paul, S. (2014). The impact of technology on skill development. The Indian Journal of Industrial Relations, 49(3), 401-408.

Pelet, J. E. (Ed.). (2013). E-Learning 2.0 technologies and web applications in higher education. New York: GI Global.

Pirani, Z., \& Sasikumar, M. (2014). Accessibility issues in learning management systems for learning disabled: A survey. In Recent advances in intelligent informatics (pp. 253-264). Springer, Cham. https:// doi.org/10.1007/978-3-31901778-526

Portz, J. D., Bayliss, E. A., Bull, S., Boxer, R. S., Bekelman, D. B., Gleason, K., \& Czaja, S. (2019). Using the technology acceptance model to explore user experience, intent to use, and use behaviour of a patient portal among older adults with multiple 
chronic conditions: descriptive qualitative study. Journal of medical Internet research, 21(4), e11604. http://dx.doi.org/10.2196/11604

Prensky, M. (2001). Digital natives, digital immigrants. In Kristine, L. B., Jen, A., \& Murphy, M. R. Crosscurrents: Cultures, communities, technologies. Boston, M. A: Wardsworth Cengage Learning

Renes, S. L. (2015). Increasing access to higher education through e-learning. E-learningInstructional design, organizational strategy and management, 10, 347-361. http://dx.doi.org/10.5772/60906

Seaman, J. (2009). Online Learning as a strategic asset: Views and experiences with online learning. The Paradox of Faculty Voices. Association of Public and Land-grant Universities.

Srichanyachon, N. (2014). EFL Learners' Perceptions of Using LMS. Turkish Online Journal of Educational Technology-TOJET, 13(4), 30-35.

Ssekakubo, G., Suleman, H., \& Marsden, G. (2011). Issues of adoption: have e-learning management systems fulfilled their potential in developing countries? In Proceedings of the South African Institute of Computer Scientists and Information Technologists Conference on knowledge, innovation, and leadership in a diverse, multidisciplinary environment (pp. 231-238).

Sun, P. C., Tsai, R. J., Finger, G., Chen, Y. Y., \& Yeh, D. (2008). What drives successful elearning? An empirical investigation of the critical factors influencing learner satisfaction. Computers $\mathcal{E} \quad$ Education, 50(4), 1183-1202. https:// doi.org/10.1016/j.compedu.2006.11.007

Tagoe, M. (2012). Students' perceptions of incorporating e-learning into teaching and learning at the University of Ghana. International Journal of Education and Development using ICT, 8(1), 91-103.

Tedre, M., Ngumbuke, F., \& Kemppainen, J. (2010). Infrastructure, human capacity, and high hopes: A decade of development of e-Learning in a Tanzanian HEI. RUSC. Universities and Knowledge Society Journal, 7(1), 7-20.

Thompson, A. A., Peteraf, M. A., Gamble, J. E., \& Strickland, A. J. (2006). Crafting and executing strategy: Concepts and cases. New York: McGraw-Hill, Irwin.

Tibyampansha, D., Ibrahim, G., Kapanda, G., Tarimo, C., Minja, A., Kulanga, A., ... \& Bartlett, J. (2017). Implementation of a learning management system for medical students: A case study of Kilimanjaro Christian Medical University College. MedEdPublish, 6, 1-13. https://doi.org/10.15694/mep.2017.0 00050

Umek, L., Keržic, D., Tomaževic, N., \& Aristovnik, A. (2015). Moodle e-learning system and students' performance in higher education: The case of public administration programmes. International Association for Development of the Information Society, 97-104.

Wang, Q., Myers, M. D., \& Sundaram, D. (2013). Digital natives and digital immigrants: Towards a model of digital fluency. BusinessE Information Systems Engineering, 5(6), 409-419.

Zhang, L., Nyheim, P., \& Mattila, A. S. (2014). The effect of power and gender on technology acceptance. Journal of Hospitality and Tourism Technology, 5(3), 299314. https://doi.org/10.1108/JHTT-03-2014-0008 